\title{
Quitosana como opção de controle do míldio para viticultura sustentável
}

\section{Chitosan as an option to control mildew in the sustainable vinegrowing}

\author{
Aline José Maia ${ }^{1 *}$; Carla Daiane Leite ${ }^{2}$; Renato Vasconcelos Botelho ${ }^{3}$; \\ Cacilda Márcia Duarte Rios Faria ${ }^{4}$; Danielle Machado ${ }^{5}$
}

\begin{abstract}
Resumo
O objetivo deste trabalho foi avaliar diferentes concentrações de quitosana na severidade do míldio e na germinação de Plasmopara viticola, além do seu efeito no desenvolvimento vegetativo das videiras cv. Cabernet Sauvignon e Merlot. Foram realizados dois experimentos. No primeiro, estacas de videira foram plantadas em vasos contendo substrato comercial Plantmax ${ }^{\circledR}$ e a areia na proporção 1:1 (v:v) e mantidas em casa de vegetação sob nebulização intermitente. A cada sete dias foram pulverizadas com soluções aquosas de quitosana nas concentrações de 0, 20, 40, 80 e $160 \mathrm{mg} \mathrm{L}^{-1}$. As folhas foram inoculadas com suspensão de esporângios de $P$. viticola 48 horas e após a segunda aplicação de quitosana. Os primeiros sintomas apareceram dez dias após a inoculação, e as avaliações da severidade foram realizadas a cada dois dias. A concentração de $160 \mathrm{mg} \mathrm{L}^{-1}$ de quitosana reduziu a severidade do míldio em 70,2 \% e 79,1 \% nas cv. Merlot e Cabernet Sauvignon, respectivamente. Testes de germinação de esporângios também foram realizados. A maior concentração de quitosana $\left(160 \mathrm{mg} \mathrm{L}^{-1}\right)$ inibiu em $50 \%$ da germinação de $P$. viticola após 24 horas. No segundo experimento, as estacas, pré-enraizadas, foram obtidas e tratadas conforme o experimento anterior. Após 60 dias em casa de vegetação, foi avaliado as seguintes variáveis: massa de raízes e folhas secas, comprimento médio de raízes e área foliar das duas cultivares. Não houve diferença significativa entre os tratamentos para as variáveis referente ao desenvolvimento de plantas.
\end{abstract}

Palavras-chave: Vitis vinifera, Plasmopara viticola, manejo de doenças, controle alternativo, agroecologia

\footnotetext{
Abstract

The aim of this study was to evaluate different concentrations of chitosan on the severity of mildew and the germination of Plasmopara viticola, in addition to its effect on vegetative growth of grapevines cv. Cabernet Sauvignon and Merlot. Two experiments were conducted. In the first vine cuttings were planted in pots with Plantmax ${ }^{\circledR}$ and sand 1:1 (v:v) and maintained in a greenhouse under intermittent mist. Every seven days were sprayed with aqueous solutions of chitosan at concentrations of $0,20,40$, 80 and $160 \mathrm{mg} \mathrm{L}^{-1}$. The leaves were inoculated with sporangia of $P$. viticola 48 hours after the second

${ }^{1}$ Doutoranda do Programa de Pós-Graduação em Proteção de Plantas, Dept ${ }^{\circ}$ de Agronomia, Universidade Estadual de Maringá, UEM, Maringá, PR. E-mail: alymaia2005@yahoo.com.br

${ }^{2}$ Prof $^{a}$ do Dept ${ }^{\circ}$ de Agronomia da Universidade Estadual do Centro-Oeste, UNICENTRO, Guarapuava, PR. E-mail: cdaianeleite@

3 Prof. Adjunto do Dept $^{\circ}$ de Agronomia da UNICENTRO, Setor Fruticultura. Bolsistas de Produtividade CNPq. E-mail: rbotelho@,

4 Prof $^{\mathrm{a}}$. Adjunto do Dept ${ }^{\mathrm{o}}$ de Agronomia da UNICENTRO, Setor Fitopatologia. E-mail: cfaria@unicentro.br

5 Mestranda do Programa de Pós-Graduação em Produção de Vegetal, Dept ${ }^{\circ}$ de Agronomia da Universidade Federal do Paraná, UFPR, Cutitiba, PR. E-mail: mdaniielle@gmail.com

* Autor para correspondência
} hotmail.com unicentro.br 
application of chitosan. The first symptoms appeared ten days after inoculation, and severity ratings were performed every two days. The concentration of $160 \mathrm{mg} \mathrm{L}^{-1}$ of chitosan decreased the severity of downy mildew in $70.2 \%$ and $79.1 \%$ in cv. Merlot and Cabernet Sauvignon, respectively. Sporangial germination tests were also conducted. The highest concentration of chitosan $\left(160 \mathrm{mg} \mathrm{L}^{-1}\right)$ inhibited by $50 \%$ germination of $P$. viticola after 24 hours. In the second experiment, cuttings, pre-rooted, were obtained and handled as the previous experiment. After 60 days in a greenhouse, we evaluated the following variables: mass of roots and leaves, root length and leaf area. There was no significant difference between treatments for the variables related to plant development.

Key words: Vitis vinifera, Plasmopara viticola, disease management, alternative control, agroecology

\section{Introdução}

Em regiões vitícolas brasileiras as doenças constituem-se num dos maiores entraves para a cultura. As doenças fúngicas são as mais prevalecentes e causam os maiores danos (GALLOTTI; JÚNIOR; SÔNEGO, 2002). Entre as principais doenças destaca-se o míldio, causado por Plasmopara viticola (Berkeley; M.A. Curtis) Berlese; De Toni, sendo responsável por prejuízos significativos em videiras na região sul do Brasil. Em regiões com alta precipitação, no final da primavera e início de verão, com manhãs de orvalho intenso, a produção pode ser perdida totalmente quando não forem efetuadas medidas de controle (SÔNEGO et al., 2008). A temperatura ideal para o desenvolvimento do patógeno é de $20^{\circ} \mathrm{C}$ a $25^{\circ} \mathrm{C}$ e a umidade ótima acima de $95 \%$. Geralmente as cultivares de uvas européias (Vitis vinifera L.) são mais suscetíveis ao míldio do que as americanas (Vitis labrusca L.) (SÔNEGO; GARRIDO, 2003).

$\mathrm{O}$ fungicida mais utilizado no controle do míldio é a calda bordalesa, composto à base de cobre. Entretanto, como todos os fungicidas cúpricos, tem o inconveniente de poder causar fitotoxidez nas partes jovens da planta (YURELA, 2005), ocasionar o acúmulo de cobre nos solos com a sua utilização ao longo dos anos, além das restrições da União Européia quanto ao seu emprego excessivo. Em função destas características, os cúpricos são recomendados apenas após a frutificação. Outros fungicidas sintéticos também são utilizados na viticultura em larga escala para o controle desta doença, tais como: metalaxyl, cymoxanil e mancozeb (AMORIM; KUNIYUKI, 2005).
Problemas de resistência do patógeno e fitotoxidez são comuns devido ao uso abusivo e despreparo dos agricultores na utilização dos agrotóxicos (PERUCH et al., 2007). Devido a tal fato, há a necessidade de desenvolvimento de pesquisas para a produção integrada, produção orgânica ou agroecológica visando utilizar técnicas alternativas para o controle de doenças da videira que, consequentemente, diminuirão o risco de contaminação do produtor, do consumidor e do ambiente (GARRIDO; SÔNEGO, 2007).

Um dos produtos alternativos que vem sendo pesquisado é a quitosana, um polissacarídeo natural extraído do exoesqueleto de artrópodes e da parede celular de fungos, pela fragmentação ou desacetilação da quitina (FORBES-SMITH, 1999).

Pesquisas já comprovam que a quitosana pode ter duplo efeito no controle de doenças de plantas: efeito antifúngico (CAMILI et al., 2007; EL GAOUTH et al., 1992) e na ativação das respostas de defesa da planta a patógenos (OH; CHO; YU, 1998). Resultados positivos com o uso de quitosana foram reportados para o controle de Botrytis cinerea em frutos de uva e morango (AIT BARKA et al., 2004; BHASKARA REDDY et al., 2000), de Puccinia arachidis em amendoim (SATHIYABAMA; BALASUBRAMANIAN, 1998) e Colletotrichum gloeosporioides, em frutos de mamão (BAUTISTABAÑOS et al., 2003).

Neste contexto, o objetivo deste trabalho foi avaliar o efeito da quitosana na severidade do míldio, na germinação de $P$. viticola, e no desenvolvimento vegetativo de videiras cv. Cabernet Sauvignon e Merlot em casa de vegetação. 


\section{Material e Métodos}

O material propagativo da videira cv. Cabernet Sauvignon e Merlot utilizado para os experimentos foram retirados do pomar experimental do Departamento de Agronomia da Universidade Estadual do Centro-Oeste (UNICENTRO), Campus CEDETEG, em Guarapuava-PR.

Para obtenção do inóculo, folhas de videira contendo sintomas de míldio, retiradas do vinhedo comercial da cv. Isabel, localizado no município de Guarapuava-PR, foram imersas em água destilada esterilizada com Tween 80 (0,5\%) e esfregadas com alça de drigalski. Após este processo foi realizada a calibração a $10^{6}$ esporângios $\mathrm{mL}^{-1}$ com o auxílio de câmara de Neubauer.

Efeito da quitosana no controle de Plasmopara viticola em estacas enraizadas de videiras $c v$. Merlot e Cabernet Sauvignon

Para avaliar o efeito da quitosana na severidade do míldio ( $P$. viticola) foi realizado teste preliminar utilizando estacas lenhosas da cv. Cabernet Sauvignon, preparadas com aproximadamente 20 $\mathrm{cm}$, contendo de três a quatro gemas cada, cortandose a porção inferior em bisel, em posição oposta à gema; e na porção superior reta, acima de uma gema. Em seguida, as estacas foram plantadas em vasos de plástico, medindo $45 \times 17 \mathrm{~cm}$ e $14 \mathrm{~cm}$ de altura, tendo como substrato areia e Plantmax ${ }^{\circledR}$, na proporção 1:1 (v:v) e mantidas em casa de vegetação sob nebulização intermitente. Após 60 dias iniciaram-se as aplicações de quitosana, com intervalos de 12 dias, totalizando 10 aplicações. As concentrações de quitosana foram: 0, 20, 40 e $80 \mathrm{mg} \mathrm{L}^{-1}$, utilizando-se o produto comercial Fish Fértil Quitosana ${ }^{\circledR}\left(20 \mathrm{~g} \mathrm{~L}^{-1}\right.$ de quitosana).

O delineamento experimental utilizado foi inteiramente casualizado com quatro tratamentos e quatro repetições com parcela experimental constituída por seis estacas. As plantas foram inoculadas com suspensão de esporângios de $P$. viticola, sete dias após a penúltima aplicação de quitosana. Os primeiros sintomas apareceram 28 dias após a inoculação. A severidade foi avaliada em oito folhas por planta, previamente identificadas, utilizando-se uma escala diagramática com valores que corresponde de $0 \%$ a $100 \%$ da área foliar lesionada (AZEVEDO, 1997), sendo realizado apenas uma avaliação.

No ano seguinte, estacas lenhosas das cv. Cabernet Sauvignon e Merlot foram preparadas com uma gema cada e introduzidas em espuma fenólicas em bandejas plásticas preenchidas com água até a altura da espuma (Figura 1A e B). Em seguida, as bandejas foram mantidas em sala de crescimento vegetativo por 60 dias com temperatura a $25^{\circ} \mathrm{C}$, e fotoperíodo de 16 horas proveniente de lâmpadas fluorescentes com uma intensidade de 2500 lux (Figura 1C). Posteriormente, as miniestacas enraizadas foram transferidas para vasos de plástico medindo $45 \times 17 \times 17 \mathrm{~cm}$, contendo como substrato Plantmax ${ }^{\circledR}$ e areia, na proporção 1:1 (v:v) e mantidas em casa de vegetação sob nebulização intermitente. (Figura 1D, E e F). As plantas foram pulverizadas a cada sete dias com soluções de quitosana nas seguintes concentrações: 0; 20;40;80 e $160 \mathrm{mg}$ $\mathrm{L}^{-1}$, utilizando-se Fish Fértil Quitosana ${ }^{\circledR}\left(20 \mathrm{~g} \mathrm{~L}^{-1}\right.$ de quitosana). No total foram realizadas 14 aplicações de quitosana.

O delineamento experimental utilizado foi inteiramente casualizado com cinco tratamentos e seis repetições e parcela experimental constituída por cinco miniestacas. As estacas foram inoculadas com suspensão de esporângios do fungo $P$. viticola, 48 horas após a segunda aplicação de quitosana. A severidade do míldio foi avaliada em quatro folhas por planta, previamente identificadas, utilizando-se a escala diagramática de Azevedo (1997). Foram realizadas oito avaliações da severidade por dois avaliadores determinando a área abaixo da curva de progresso da doença (AACPD), segundo Shaner e Finney (1977). 
Figura 1. Modo de preparo das mudas de videira cv. Merlot e Cabernet Sauvignon. (A) estacas preparadas com duas gemas cada; (B) estacas introduzidas em espuma fenólica em bandejas plásticas preenchidas com água; (C) sala de crescimento vegetativo por 60 dias com temperatura a $25^{\circ} \mathrm{C}$; (D) miniestacas enraizadas; (E) miniestacas enraizadas transferidas para vasos de plástico contendo substrato e $(\mathrm{F})$ casa de vegetação.



Fonte: Elaboração dos autores.

Efeito das concentrações de quitosana sobre a germinação de Plasmopara viticola

Para avaliar o efeito da quitosana sobre a germinação de $P$. viticola utilizou-se uma alíquota de $40 \mu 1$ da suspensão de esporângios e outra de 40 $\mu 1$ de cada concentração de quitosana $(0,20,40$, 80 e $160 \mathrm{mg} \mathrm{L}^{-1}$ ), além de uma única dose de calda bordalesa e mancozeb como tratamento padrão, não autoclavados. A calda bordalesa foi preparada na proporção 1:1:100 (sulfato de cobre/cal virgem/ água) e o mancozeb (Manzate ${ }^{\circledR} 800$, fabricado por Dow AgroSceinces industrial LTDA, Barueri, SP/titular do registro DU PONT do Brasil S.A.) foi empregado na dose indicada no rótulo para a cultura. Estes foram colocados em cada um dos recipientes ("pocinhos") de uma placa utilizada em teste ELISA (REGENTE et al., 1997). As placas foram incubadas sob luz constante a $20^{\circ} \mathrm{C} \pm 1{ }^{\circ} \mathrm{C}$. A porcentagem de germinação foi determinada às 24 horas, após o início do experimento, através do emprego de $20 \mu 1$ de lactofenol com azul de algodão para fixação. A avaliação foi realizada através da observação ao microscópio ótico com aumento de 400 vezes. Contaramse 100 esporângios aleatórios por repetição, totalizando 400 esporângios por tratamento. Foram considerados esporângios germinados aqueles que apresentavam liberação dos zoósporos (Figura 2). Este experimento foi conduzido duas vezes. Os resultados foram submetidos à análise de variância e regressão polinomial e comparação de média a 5 $\%$ probabilidade, através do programa estatístico SISVAR (FERREIRA, 2008). 
Figura 2. Esporângio de Plasmopara viticola germinado.

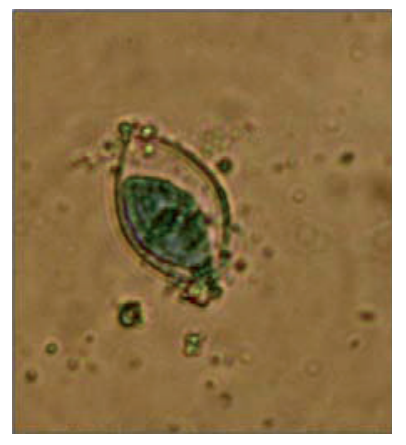

Fonte: Elaboração dos autores.

Efeito da quitosana no desenvolvimento vegetativo de videiras cv. Cabernet Sauvignon e Merlot

Estacas pré-enraizadas das cv. Cabernet Sauvignon e Merlot foram preparadas conforme o experimento da severidade do míldio. O delineamento experimental utilizado foi inteiramente casualizado com cinco tratamentos e seis repetições e parcela experimental constituída por cinco miniestacas.

As plantas foram pulverizadas a cada sete dias com soluções de quitosana nas seguintes concentrações: 0, 20, 40, 80 e $160 \mathrm{mg} \mathrm{L}^{-1}$, utilizandose Fish Fértil Quitosana ${ }^{\circledR}$ (20 g L $^{-1}$ de quitosana), com um total de 14 aplicações com quitosana.

Após 60 dias em casa de vegetação, foram avaliadas as seguintes variáveis: massa de folhas e de raízes secas, comprimento de raízes e área foliar. Para a variável massa de folhas e raízes secas foi feita a secagem em estufa com circulação de ar forçado a $70{ }^{\circ} \mathrm{C}$, até atingir peso constante. $\mathrm{O}$ comprimento médio das raízes foi avaliado conforme a metodologia proposta por Tennant (1975). A área foliar foi realizada por meio do programa IMAGE J Windows XP.

Os resultados obtidos foram submetidos à análise de variância e regressão polinomial a $5 \%$ probabilidade, utilizando o programa estatístico SISVAR (FERREIRA, 2008).

\section{Resultados e Discussão}

Efeito da quitosana no controle de Plasmopara viticola em estacas enraizadas de videiras $c v$. Merlot e Cabernet Sauvignon

No teste preliminar, observou-se efeito linear negativo da severidade da doença em função das doses pré-estabelecidas de quitosana para a cv. Cabernet Sauvignon, quando comparado com a testemunha. O decréscimo observado foi de 76,8\% na dose de $80 \mathrm{mg} \mathrm{L}^{-1}$ quitosana. Verificou-se redução na severidade do míldio com o aumento da dose de quitosana aplicada (Figura 3). De forma similar, no experimento realizado no ano seguinte, para os resultados de AACPD houve efeito linear negativo em função das doses de quitosana para ambas as cultivares (Figuras 4 e 5). A redução atingiu 70,2 \% e $79,1 \%$ na dose de $160 \mathrm{mg} \mathrm{L}^{-1}$ de quitosana para as cv. Merlot e Cabernet Sauvignon, respectivamente.

Nos resultados obtidos neste estudo, a quitosana reduziu a severidade do míldio, in vivo. Estes resultados são concordantes com aqueles obtidos por Aziz et al. (2006) que verificaram que quitosana a $200 \mu \mathrm{g} \mathrm{mL} \mathrm{m}^{-1}$ pulverizada isoladamente ou combinada com sulfato de cobre $\left(\mathrm{CuSO}_{4}\right)$ a 50 $\mu \mathrm{g} \mathrm{mL}^{-1}$ sobre folhas de videira cv. Chardonnay reduziram a severidade de $P$. viticola, em $71 \%$ e 85 $\%$, respectivamente. Apesar dos resultados serem semelhantes, cabe ressaltar que o trabalho citado, foi realizado na França, com outra variedade de uva e outra fonte de quitosana, o que demostra a importância de pesquisas com quitosana em outras condições ambientais e com outras variedades de videira, como no caso deste trabalho realizado em Guarapuava-PR. Di Piero e Garda (2008), avaliando o controle da antracnose em feijoeirocomum com o uso de diferentes doses de quitosana, também verificaram redução da severidade da doença em torno de $70 \%$, quando utilizada a dose de $9 \mathrm{mg}$ de quitosana por planta, quatro dias antes da inoculação de Colletotrichum lindemuthianum. Resultados semelhantes foram obtidos também por Rodrigues, Bezerra Neto e Coelho (2006), que 
observaram que a quitosana, quando pulverizada no primeiro par de folhas de caupi, aos cinco dias após a germinação, proporcionou o controle da murcha de Fusarium oxysporum em 65,4 \%. Estes resultados comprovam um efeito da quitosana na interação patógeno-hospedeiro, ou seja, ação direta sobre o desenvolvimento do patógeno $(\mathrm{OH} ; \mathrm{CHO}$; YU, 1998).

Figura 3. Efeito das concentrações de quitosana, na severidade do míldio da videira, na cv. Cabernet Sauvignon. * significativo a $1 \%$ de probabilidade (Guarapuava-PR, 2007).

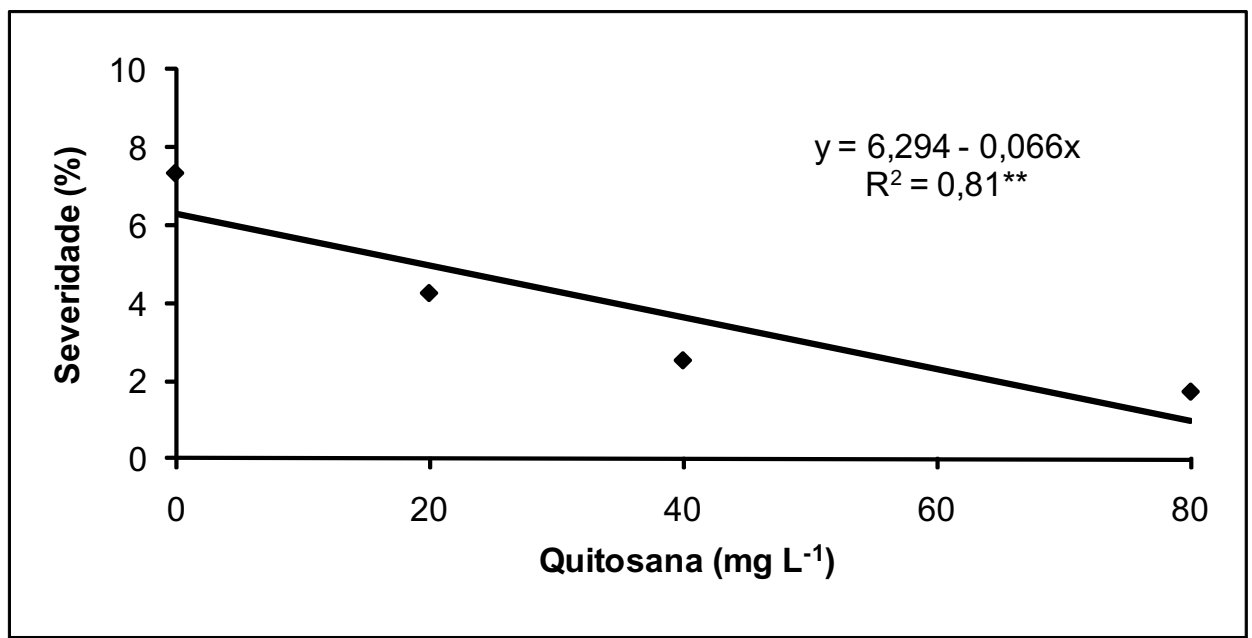

Fonte: Elaboração dos autores.

Figura 4. Efeito das concentrações de quitosana, na área abaixo da curva de progresso da doença (AACPD), sobre o míldio na cv. Merlot. " significativo a 1\% de probabilidade (Guarapuava-PR, 2008).

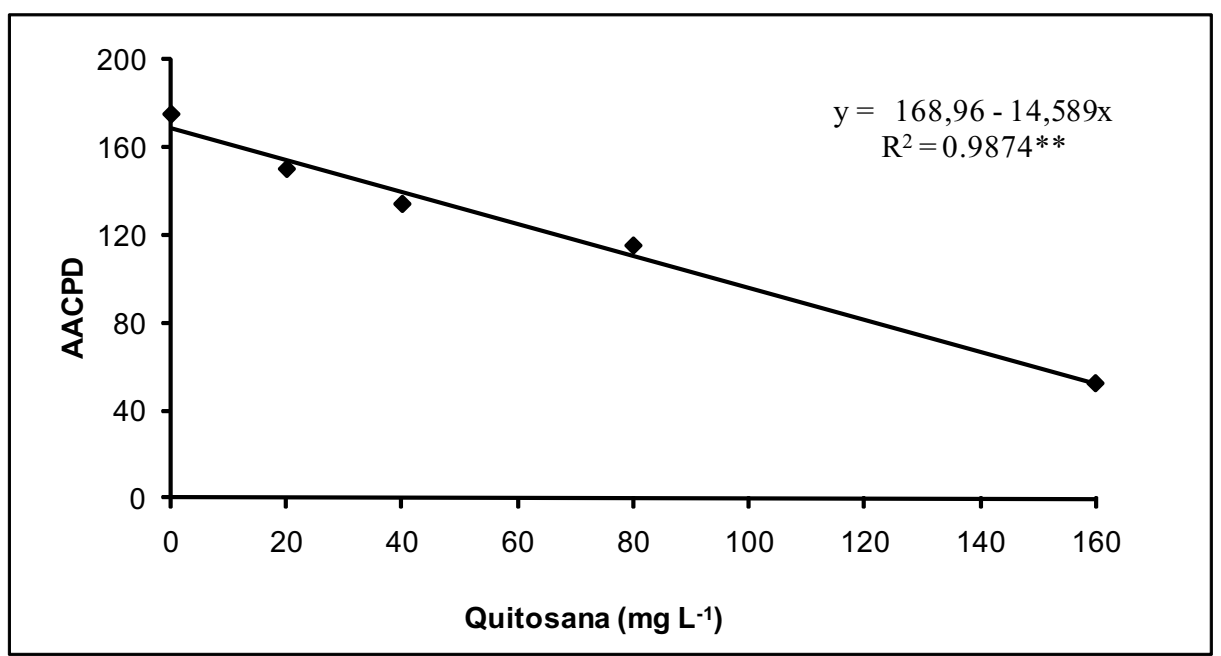

Fonte: Elaboração dos autores. 
Figura 5. Efeito das concentrações de quitosana, na área abaixo da curva de progresso da doença (AACPD), sobre o míldio na cultivar Cabernet Sauvignon. * significativo a 1\% de probabilidade (Guarapuava-PR, 2008).

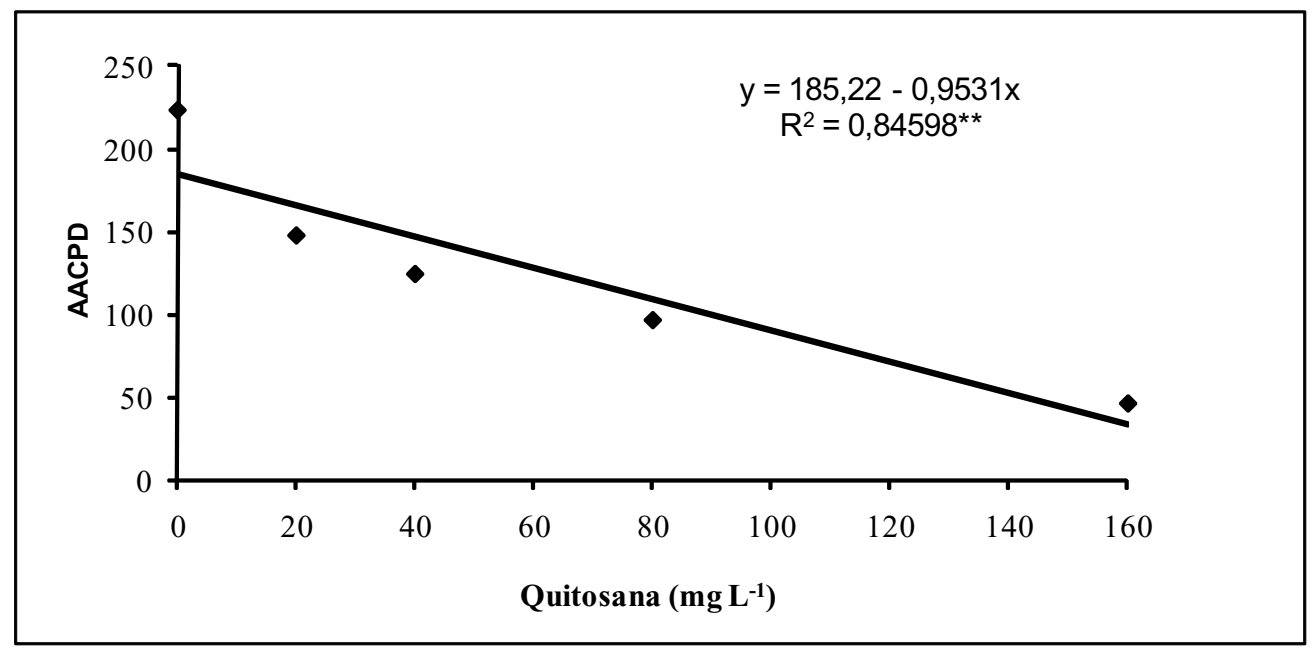

Fonte: Elaboração dos autores.

Produtos a base de quitosana podem ser usados também em pós-colheita, para retardar a severidade das doenças causadas por diferentes patógenos. Entre os mecanismos envolvidos encontra-se o efeito direto sobre o patógeno, a indução de mecanismos de resistência no hospedeiro e a prevenção de contaminantes quando utilizado para tratar ferimentos (EL GHAOUTH et al., 1992; BEN-SHALON et al., 2003; LIU et al., 2007). Camili et al. (2007), com o objetivo de avaliar o efeito da quitosana na proteção pós-colheita de cachos de uva 'Itália' contra Botrytis cinerea e seu efeito sobre o desenvolvimento do patógeno in vitro, verificaram que o crescimento micelial do fungo foi completamente inibido pelas concentrações de quitosana a 0,$5 ; 1,0 ; 1,5$ e $2,0 \%$ durante o período de incubação de cinco dias a $22 \pm 1{ }^{\circ} \mathrm{C}$. Da mesma forma, El Gaouth et al. (1992) demonstraram que soluções de quitosana a $10 \mathrm{mg} \mathrm{L}^{-1}$, diminuíram a incidência de doenças em frutos inoculados com B. cinerea e Rhizopus stolonifer. Já Botelho et al. (2010), verificaram redução na podridão causada por Penicillium sp. em maçã cv. Castel Gala e Princesa a partir da concentração de $10 \mathrm{mgL}^{-1}$ do mesmo produto comercial utilizado no presente trabalho.
No entanto, trabalhos realizados por Vander et al. (1998) demonstraram que a quitosana pode induzir a atividade da enzima PAL (fenilalanina amônia liase) e respostas biológicas, como a produção e acúmulo de fitoalexinas em milho e videira, o que também foi comprovado por Romanazzi et al. (2002) em videiras. Aziz et al. (2006) obtiveram a máxima indução na atividade das enzimas quitinases e $\beta$-1,3-glucanase quando utilizou 300 $\mathrm{mg} \mathrm{mL} \mathrm{m}^{-1}$ de oligômeros de quitosana em videiras $\mathrm{cv}$. Chandonnay, comprovando assim o segundo efeito pela quitosana: ativação das respostas de defesa da planta, sugerido por Oh, Cho e Yu (1998). Neste trabalho não foi verificada a ação da quitosana induzindo a atividade enzimática, devendo esta ação ser estudada posteriormente, em outros ensaios.

Efeito das concentrações de quitosana sobre a germinação de Plasmopara viticola

No ensaio realizado para verificar a germinação de $P$. viticola houve efeito quadrático em função das doses de quitosana, sendo que a dose de $160 \mathrm{mg} \mathrm{L}^{-1}$ inibiu a germinação em aproximadamente $50 \%$ em 24 horas após a incubação quando comparados com 
a testemunha. Não houve diferença estatística entre as doses de quitosana e os tratamentos mancozeb e calda bordalesa. Pode-se observar também que, todas as doses utilizadas diminuíram a germinação, não diferindo entre si (Figura 6).

Figura 6. Germinação de esporângios de Plasmopara viticola, em diferentes concentrações de quitosana, mancozeb e calda bordalesa às 24 horas após incubação a $25^{\circ} \mathrm{C}$. * significativo a $1 \%$ de probabilidade (Guarapuava-PR, 2008).

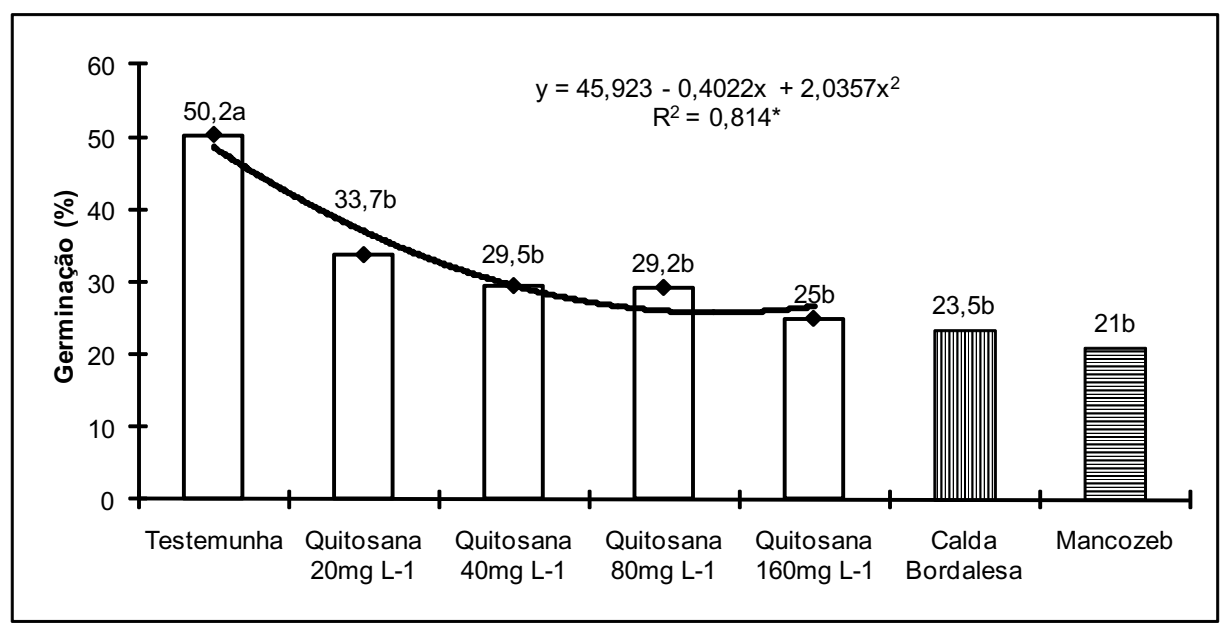

Fonte: Elaboração dos autores.

O efeito da quitosana na germinação de esporos de fitopatógenos foi relatado por diversos autores. El Ghaouth et al. (1992) observaram a redução de 95 e $75 \%$ na germinação de esporos de $B$. cinerea e de $R$. stolonifer isolados de morango em doses de $6000 \mu \mathrm{g} \mathrm{ml}^{-1}$, respectivamente, enquanto que a dose de $100 \mu \mathrm{g} \mathrm{L}^{-1}$ reduziu em $75 \%$ a germinação de uredosporos de Puccinia arachidis, agente causal da ferrugem do amendoim (SATHIYABAMA; BALASUBRAMANIAN, 1998).

Já Ben-Shalom et al. (2003), observaram que a quitosana a $50 \mu \mathrm{g} \mathrm{L}$ inibiu a germinação de esporos e reduziu a elongação do tubo germinativo de B. cinerea. Cia (2005), avaliando o efeito da quitosana sobre $C$. gloeosporioides, agente causal da antracnose em mamão, observou que doses a partir de $2500 \mu \mathrm{g} \mathrm{mL}$ inibiram completamente a germinação do fungo in vitro. Contudo, a mesma dose não inibiu a germinação de $B$. cinerea isolado de uvas por Camili et al. (2007), porém resultou em alterações morfológicas do tubo germinativo.
Também foi verificado a inibição completa da germinação de Penicillium expansum, agente causal do bolor azul em tomates quando utilizou-se a dose de $5000 \mu \mathrm{g} \mathrm{mL}$ (LIU et al., 2007).

Estudos sugerem que a ação da quitosana sobre a germinação de esporos de alguns fungos acontece por alterações na parede celular, danos à membrana plasmática e no vacúolo. Trabalhos demonstram que a quitosana causou danos à membrana plasmática de $B$. cinerea e $P$. expansum (LIU et al., 2007), enquanto que os danos à parede celular e ao vacúolo, como também, em alguns casos notaram a desintegração do patógeno (EL GHAOUTH et al., 1994).

\section{Efeito da quitosana no desenvolvimento vegetativo} de videiras cv. Cabernet Sauvignon e Merlot

Para as variáveis massas de folhas e raízes secas, comprimento médio de raízes e índice da área foliar não houve diferenças significativas entre os 
tratamentos para as cultivares Merlot e Cabernet Sauvignon (Tabelas 1 e 2). Além disso, não foram observados sintomas de fitotoxidez nas folhas.

Estes resultados são discordantes daqueles obtidos para a cv. Merlot por Maia et al. (2010) que, em condições in vitro verificaram que para as variáveis, comprimento médio da parte aérea, massa fresca da planta inteira, porcentagem de estacas enraizadas e porcentagem de estacas brotadas houve decréscimo linear em função das doses de quitosana $\left(0,50,100,150\right.$ e $\left.200 \mathrm{mgL}^{-1}\right)$.

Tabela 1. Massa de folhas e raízes secas, comprimento médio de raízes e área foliar de plântulas de videira cv. Merlot, pulverizadas com as diferentes concentrações de quitosana (Guarapuava-PR, 2008).

\begin{tabular}{ccccc}
\hline $\begin{array}{c}\text { Tratamento } \\
\left(\mathrm{mg} \mathrm{L}^{-1}\right)\end{array}$ & $\begin{array}{c}\text { Massa de folhas secas } \\
(\mathrm{mg}) *\end{array}$ & $\begin{array}{c}\text { Massa de raízes secas } \\
(\mathrm{mg}) *\end{array}$ & $\begin{array}{c}\text { Comprimento médio } \\
\text { de raízes }(\mathrm{cm}) *\end{array}$ & $\begin{array}{c}\text { Área foliar } \\
(\mathrm{cm}) * *\end{array}$ \\
\hline 0 & 228 & 2087 & 3678,009 & 452,785 \\
20 & 253 & 1665 & 3938,737 & 458,888 \\
40 & 235 & 1775 & 3374,372 & 448,763 \\
80 & 191 & 1574 & 4646,722 & 337,264 \\
160 & 240 & 1911 & 3675,806 & 449,874 \\
CV\% & 33,52 & 20,58 & 47,35 & 28,66 \\
$\mathbf{P r}>\mathbf{F c}$ & $0.6977^{\text {ns }}$ & $0,1615^{\text {ns }}$ & $0,795^{\text {ns }}$ & $0.3972^{\text {ns }}$ \\
\hline
\end{tabular}

ns = não significativo pelo teste de Tukey a $5 \%$ de probabilidade * média por estaca, $* *$ média por parcela experimental.

Fonte: Elaboração dos autores.

Tabela 2. Massa de folhas e raízes secas, comprimento médio de raízes e área foliar de plântulas de videira cv. Cabernet Sauvignon, pulverizadas com as diferentes concentrações de quitosana (Guarapuava-PR, 2008).

\begin{tabular}{ccccc}
\hline $\begin{array}{c}\text { Tratamento } \\
\left(\mathrm{mg} \mathrm{L}^{-1}\right)\end{array}$ & $\begin{array}{c}\text { Massa de folhas } \\
\text { secas }(\mathrm{mg}) *\end{array}$ & $\begin{array}{c}\text { Massa de raízes } \\
\text { seca }(\mathrm{mg}) *\end{array}$ & $\begin{array}{c}\text { Comprimento médio } \\
\text { de raízes }(\mathrm{cm}) *\end{array}$ & $\begin{array}{c}\text { Área foliar } \\
(\mathrm{cm}) * *\end{array}$ \\
\hline 0 & 211 & 399 & 4276,976 & 506,927 \\
20 & 215 & 335 & 3798,542 & 370,581 \\
40 & 155 & 259 & 3658,482 & 311,695 \\
80 & 230 & 394 & 3421,432 & 454,686 \\
160 & 222 & 347 & 3251,673 & 439,61 \\
CV $\%$ & 44,00 & 43,84 & 41,36 & 30,65 \\
$\mathbf{P r}>\mathbf{F c}$ & $0,6449^{\text {ns }}$ & $0,4660^{\text {ns }}$ & $0,8054^{\text {ns }}$ & $0.2334^{\text {ns }}$ \\
\hline
\end{tabular}

${ }^{\mathrm{ns}}=$ não significativo pelo teste de Tukey a $5 \%$ de probabilidade. ${ }^{*}$ média por estaca, ${ }^{*} *$ média por parcela experimental.

Fonte: Elaboração dos autores.

Ait Barka et al. (2004) verificaram que a adição de $1,75 \%(\mathrm{v} / \mathrm{v})$ de chitogel, produto à base de quitosana, em meio de cultura promoveu aumento no comprimento das brotações e peso de raízes de plântulas cv. Chardonnay e a concentração de $2 \%$ de chitogel teve um efeito negativo no crescimento das plântulas, sendo que concentrações maiores do produto promoveram morte das plantas. Esta discrepância de resultados pode ser creditada as diferenças na condução dos experimentos e formulação da quitosana usado nos dois trabalhos.

De acordo com os resultados deste trabalho, a utilização de quitosana como medida alternativa aos fungicidas para o controle do míldio da videira, pode ser viável do ponto de vista socioeconômico e ambiental, por ser uma substância natural obtida 
de resíduos da indústria pesqueira, barata e atóxica. Nas doses testadas neste experimento, a quitosana, demonstrou ser eficiente no controle do míldio da videira sem causar fitotoxidez ou qualquer alteração do desenvolvimento vegetativo das cv. Cabernet Sauvignon e Merlot. O que a torna uma boa alternativa para a produção integrada e produção orgânica. A alternância de aplicações da calda bordalesa com outros compostos alternativos, como produtos a base de quitosana, pode ser estratégia interessante no manejo do míldio da videira, entretanto, novas pesquisas necessitam ser realizadas para melhor elucidar o modo de ação da quitosana no controle do míldio da videira.

\section{Agradecimentos}

À Coordenação de Aperfeiçoamento de Pessoal Nível Superior - CAPES pela bolsa de mestrado concedida ao primeiro autor.

Á Fundação Araucária/SETI pela bolsa de mestrado concedida ao segundo autor.

\section{Referências}

AIT BARKA, E.; EULLAFFROY, P.; CLÉMENT, C.; VERNET, V. Chitosan improves development, and protects Vitis vinifera L. against Botrytis cinerea. Plant Cell Reports, Heidbelberg, v. 22, n. 8, p. 608-614, 2004.

AMORIM, L.; KUNIYUKI, H. Doenças da videira. In: KIMATI, H.; AMORIM, L.; REZENDE, J. A. M.; BERGAMIN FILHO, A.; CAMARGO, L. E. A. (Ed.). Manual de fitopatologia: doenças das plantas cultivadas. 4. ed. São Paulo: [s.n.], 2005. v. 2, p. 639-651.

AZEVEDO, L. A. S. Quantificação de doenças. In: . Manual de quantificação de doenças de plantas. São Paulo: Novartis Biociências/Setor Agro, 1997. cap. 9, p. 101-101.

AZIZ, A.; TROTEL-AZIZ, P.; DHUICQ, L.; JEANDET, P.; COUDERCHET, M.; VERNET, G. Chitosan oligomers and copper sulfate induce grapevine defense reactions and resistance to gray mold and downy mildew. Phytopathology, Saint Paul, v. 96, n. 11, p. 1188-1194, 2006.

BAUTISTA-BAÑOS, S.; HERNÁNDEZ-LÓPEZ, M.; BOSQUEZ-MOLINA, E.; WILSON, C. L. Effects of chitosan and extracts on growth of Colletotrichum gloeosporioides, anthracnose levels and quality of papaya fruit. Crop Protection, London, v. 22, n. 9, p. 1087-1092, 2003.

BHASKARA REDDY, M. V.; BELKACEMI, K.; CORCUFF, R.; CASTAIGNE, F.; ARUL, J. Effect of pre-harvest chitosan sprays on pos-harvest infection by Botritis cinerea and quality of strawberry fruit. Postharvest Biology and Technology, Amsterdam, v. 20, n. 1, p. 39-51, 2000.

BEN-SHALOM, N.; ARDI, R.; PINTO, R.; AKI, C.; FALLIK, E. Controlling graymold caused by Botrytis cinerea in cucumber plants bymeans of chitosan. Crop Protection, London, v. 22, n. 2, p. 285-290, mar. 2003.

BOTELHO, R. V.; MAIA, A. J.; RICKLI, E. H.; LEITE, C. D.; FARIA, C. D. R. Quitosana no controle de Penicillium sp. na pós-colheita de maças. Revista Brasileira de Agroecologia, Porto Alegre, v. 2, n. 5, p. 2000-2006, 2010.

CAMILI, E. C.; BENATO, E. A.; PASCHOLATI, S. F.; CIA, P. Avaliação de quitosana, aplicada em pós colheita, na proteção de uva 'Itália'contra Botrytis cinerea. Summa Phytopathologica, Botucatu, v. 33, n. 3, p. 215-221, 2007.

CIA, P. Avaliação de agentes bióticos e abióticos na indução de resistência e no controle pós-colheita $\mathrm{da}$ antracnose (Colletotrichum gloeosporioides) em mamão (Carica papaya). 2005. Tese (Doutorado em Fitopatologia) - Escola Superior de Agricultura Luiz de Queiroiz ESALQ, Piracicaba.

DI PIERO, M. D.; GARDA, M. V. Quitosana reduz a severidade da antracnose e aumenta a atividade de glucanases em feijoeiro-comum. Pesquisa Agropecuária Brasileira, Brasília, v. 43, n. 9, p. 1121-1128, 2008.

EL-GAOUTH, A.; ARUL, J.; GRENIER, J.; ASSELIN, A. Antifungal activity of chitosan on two postharvest pathogens of strawberry fruits. Phytopathology, St. Paul, v. 82, n. 4, p. 398-402, 1992.

EL-GHAOUTH, E. A.; ARUL, J.; WILSON, C.; BENHAMOU, N. Ultrastructural and cytochemical aspects of the effect of chitosan on decay of bell pepper fruit. Physiological and Molecular Plant Pathology, London, v. 44, n. 6, p. 417-422, 1994.

FERREIRA, D. F. SISVAR: um programa para análises e ensino de estatística. Revista Cientifica Symposium, Lavras, v. 6, n. 2, p. 36-41, 2008.

FORBES-SMITH, M. Induced resistance for the biological control of postharvest diseases of fruit and vegetables. Food Austrália, North Sidney, v. 51, n. 8, p. 382-385, 1999. 
GALLOTTI, G. J. M.; JÚNIOR, A. G.; SÔNEGO, O. R. Controle das doenças de plantas da videira. In: ZAMBOLIM, L. et al. Controle de doenças de plantas frutíferas. Viçosa: UFV, 2002. v. 2, cap. 15, p. 939-985.

GARRIDO, R. L.; SÔNEGO, R. O. Manejo de doenças de videira. In: NEF/UFLA (Org.). Manejo integrado de doenças de fruteiras. 2007. Lavras: Sociedade Brasileira de Fitopatologia, 2007. cap. 4, p. 65-86.

LIU, L.; TIAN, S.; MENG, X.G.; XU, Y. Effects of chitosan on control of postharvest diseases and hysiological responses of tomato fruits. Postharvest Biology and Tecnology, Amsterdam, v. 44, n. 3, p. 300306, june 2007.

MAIA, A. J.; LEITE, C. D.; BOTELHO, R. V.; FARIA, C. M. D. R.; UBER, S. C. Efeitos da quitosana no desenvolvimento in vitro de videiras cv. Merlot e no crescimento micelial do fungo Elsinoe ampelina. Ciências e Agrotecnologia, Lavras, v. 34, n. 6, p. 14251430, 2010.

OH, S. K.; CHO, D.; YU, S. H. Development of integrated pest management techniques using biomass for organic farming (I). Suppression of late blight and fusarium wilt of tomato by chitosan involving both antifungal and plant activating activities. Korean Society of Plant Pathology, Suwon, v. 14, n. 1, p. 278-285, 1998.

PERUCH, L. A. M.; MEDEIROS, A. M.; BRUNA, E. D.; STADINIK, M. Biomassa cítrica, extrato de algas, calda bordalesa e fosfitos no controle do míldio da videira, cv. Niágara Branca. Revista de Ciências Agroveterinárias, Lages, v. 6, n. 2, p. 143-148, 2007.

REGENTE, M. C.; OLIVA, C. R.; FELDMAN, M. L.; CASTAGNARO, A. P.; LACANAL, L. Sunflower leaf antifungal peptide active against Sclerotinia sclerotiorum. Physiologia Plantarum, Dordrecht, v. 100, n. 1, p. 178182, 1997.

RODRIGUES, A. A. C.; BEZERRA NETO, E.; COELHO, R. S. B. Indução de resistência a Fusarium oxysporum f. sp. tracheiphilum em caupi: eficiência de indutores abióticos e atividade enzimática elicitada. Fitopatologia Brasileira, Brasília, v. 31, n. 5, p. 492-499, 2006.
ROMANAZZI, G.; NIGRO, F.; IPPOLITO, A.; DI VENERE, D.; SALERNO, M. Effect of pre- and postharvest chitosan treatments to control storage grey mold of table grapes. Journal of Food Science, Chicago, v. 67, n. 5 , p. $1862-1867,2002$.

SATHIYABAMA, M.; BALASUBRAMANIAM, R. Chitosan induces resistance components in Arachis hipogaea against leaf rust caused by Puccinia arachidis Speg. Crop Protection London, v. 17, n. 4, p. 307-313, 1998.

SHANER, G.; FINNEY, R. The effect of nitrogen fertilization on the expression of slow mildewing resistence in Knox Wheat. Journal of Phytopathology, Saint Paul, v. 67, n. 8, p. 1051-1056, 1977.

SÔNEGO, O. R.; GARRIDO, L. R. Uvas para processamento fitossanidade. Empresa Brasileira de Pesquisa Agropecuária, 2003, 188 p.

SÔNEGO, O. R.; GARRIDO, L. da R.; GRIGOLETTI JUNIOR, A. Principais doenças fúngicas da videira no Sul do Brasil. 2005. (Circular Técnico Embrapa Uva e Vinho). Disponível em: <http:// www.cnpuv.embrapa.br/ publica/circular/cir056.pdf/>. Acesso em: 16 jul. 2008.

SATHIYABAMA, M.; BALASUBRAMANIAM, R. Chitosan induces resistance components in Arachis hipogaea against leaf rust caused by Puccinia arachidis Speg. Crop Protection London, v. 17, n. 4, p. 307-313, 1998.

TENNANT, D. A test of a modified line intersect method of estimating root length. The Journal of Ecology, Oxford, v. 63, n. 3, p. 995-1001, 1975.

VANDER, P.; VARUM, K. M.; DOMARD, A.; ELGUEDDARI, N. E.; MOERSCHBACHER, B. M. Comparison of the ability partially $\mathrm{N}$-acetylated chitosans and chitooligosaccharides to elicit resistance reactions in wheat leaves. Plant Physiology, Illinois, v. 118, n. 4, p. 1353-1359, 1998.

YRUELA, I. Copper in plants. Brazilian Journal of Plant Physiology, Viçosa, v. 17, n. 2, p. 145-156, 2005. 
